\title{
Modelling of Water Flow and Nitrate Dynamics Through Partially Saturated Porous Media in Laboratory Condition using Hydrus-2D
}

\author{
${ }^{1^{*} J a h a n g e e r,}{ }^{2}$ P.K. Gupta and ${ }^{2}$ B. Yadav \\ ${ }^{1}$ Visiting Research intern, University of Nebraska Lincoln, USA \\ ${ }^{2}$ Department of Hydrology, Indian Institute of Technology Roorkee, India \\ *Email:jahangeer.tomar@gmail.com
}

\begin{abstract}
Due to the reducing availability of water resources and the growing competition for water between residential, industrial, and agricultural users, increasing irrigation efficiency, by several methods like drip irrigation, is a demanding concern for agricultural experts. The understanding of the water and contaminants flow through the subsurface is needed for the sustainable irrigation water management, pollution assessment, remediation, and groundwater recharge. In this study, the Windows-based computer software package HYDRUS-2D, which numerically simulates water and solute movement in two-dimensional, variably-saturated porous media, was used to evaluate the distribution of water and Nitrate in the sand tank. The laboratory and simulation experiments were conducted to evaluate the role of drainage, recharge flux, and infiltration on subsurface flow condition and subsequently, on nitrate movement in the subsurface. The water flow in the unsaturated zone was model by Richards' equation, which was highly nonlinear and its parameters were largely dependent on the moisture content and pressure head of the partially saturated zone. Following different cases to be considered to evaluate- a) applying drainage and recharge flux to study domains, b) transient infiltration in a vertical soil column and c) subsequently, nitrate movement in a 2D sand tank setup. A single porosity model was used for the simulation water and nitrate flow in the study domain. The results indicate the transient water table position decreases as the time increase significantly by applying drainage flux at the bottom. Similarly, the water table positions in study domains increasing in the domain by applying recharge flux. Likewise, the water flow profile shows the decreasing water table elevation with increasing water content in the vertical domain. Furthermore, the nitrate transport dynamics was dominated by advective flux and highly affected by the recharge flux in the vertical direction. The findings of the study help to enhance the understanding of the sustainable soil-water resources management and agricultural practices.
\end{abstract}

Indexed Terms- Partially saturated porous media; Water flow; Nitrate; HYDRUS 2D.

\section{INTRODUCTION}

The water flows in partially saturated zones are the most important mechanisms of the water cycle. The water flows through the zones are important to the soil ecology and the groundwater development. The knowledge on the water flow through the unsaturated zones is needed for the sustainable irrigation water management, drip irrigation, soil-water conservation measures, pollution assessment, remediation and groundwater recharge [1]. The different mathematical models are used for the simulation of the water and solute flux in the partially saturated zones. Usually, the water flow in the unsaturated zone is described by Richards' equation. Since this equation is highly nonlinear and its parameters are largely dependent on the soil moisture content and pressure head of the partially saturated zone [2], it is difficult to obtain an analytic solution of Richards' equation, except for special conditions. The finite difference method and the finite element method are used to solve Richards' 
equation. Meanwhile, some simulation software like Tough2 [3], Hydrus-1/2/3D [4], VSAFT2 [5], and VSAFT3 [6] have also been developed. The HYDRUS software offers finite element numerical solution of Richards' equation which is water flow through unsaturated porous media [7].

In the few studies analyzing transport under transient water flow, transient flow was induced by varying the water infiltration rate at the soil surface, which, in most cases, does not lead to large variations of water saturation in the bottom part of the domain. Transient water flow in the soil can also result from time-variable lower boundary conditions [8]. There are few reported experiments, however, concerning transient flow obtained from time-variable bottom boundary conditions. This is due to the fact that, under natural conditions, the unsaturated zone is deep and exhibits little variation in moisture and pressure head at its base [9]. Therefore, in this work s, the different cases of transient water flow and solute transport condition consider for the simulation of the partially saturated flow. The aim of this study is to simulate the water flow and solute movement under transient conditions in the partially saturated zone.

\section{GOVERNING EQUATION}

The governing flow equation for uniform flow is given by the following modified form of the Richards' equation [10].

$$
\frac{\partial \theta}{\partial t}=\frac{\partial}{\partial x_{i}}\left[K\left(K_{i j}^{A} \frac{\partial h}{\partial x_{j}}+K_{i z}^{A}\right)\right]-S
$$

Where $\theta$ is the volumetric water content $\left[\mathrm{L}^{3} \mathrm{~L}^{-3}\right], K_{i j}^{A}$ are components of a dimensionless anisotropy tensor $\mathrm{K}^{\mathrm{A}}, \mathrm{S}$ is a sink term $\left[\mathrm{T}^{-1}\right], \mathrm{h}$ is the pressure head[L], $\mathrm{xi}(\mathrm{i}=1,2)$ are the spatial coordinate[L], $\mathrm{t}$ is time[T], and $\mathrm{K}$ is the unsaturated hydraulic conductivity function $\left[\mathrm{LT}^{-1}\right]$ is given by

$$
\mathrm{K}(h, x, y)=\mathrm{K}_{\mathrm{s}}(\mathrm{x}, \mathrm{y}) \mathrm{K}_{\mathrm{r}}(\mathrm{h}, \mathrm{x}, \mathrm{y})
$$

Where $\mathrm{K}_{\mathrm{s}}$ and $\mathrm{K}_{\mathrm{r}}$ are the saturated and the relative hydraulic conductivity respectively.

To solve this equation, explicit expressions for the soil constitutive relationship between the dependent variable $\mathrm{h}$ and the nonlinear terms $\mathrm{K}$ and $\theta$ are required. Many soil moisture constitutive relationships reported in the literature, the most popular ones are by Van Genuchten (1980) [2]. The closed form $\theta$-h relationship developed by fitting mathematical equations to field experiments data yields.

$$
\theta(h)=\left\{\begin{array}{c}
\theta_{s} \\
\theta_{r}+\left[\theta_{s}-\theta_{r}\right] /\left[1+|\alpha h|^{n}\right]^{n} \begin{array}{l}
h \geq 0 \\
h<0
\end{array}
\end{array}\right.
$$

where $\theta \mathrm{s}$ is the saturated water content, $\theta \mathrm{r}$ is the residual water content (irreducible) and $\theta$ is the moisture content at soil matrix potential, $\mathrm{h}$. $\mathrm{n}, \mathrm{m}, \alpha$ are curve fitting parameters Likewise, Van Genuchten (1980) [2] used the statistical pore size distribution model of [11] along with equation 2a to yield the K-h relationship.

$$
K(h)=\left\{\begin{array}{cc}
K_{s} & h \geq 0 \\
K_{s} \frac{\left\{1-(\alpha h)^{n-1}\left[1+(\alpha h)^{n}\right]^{-m}\right\}^{2}}{\left\{1+(\alpha h)^{n}\right\}^{m / 2}} & h<0
\end{array}\right.
$$

\section{METHODOLOGY}


A two-dimensional sand tank was fabricated to conduct the laboratory experiments. The sand tank setup is made of $0.7 \mathrm{~mm}$ thick glass sheet and stainless steel embedded with three horizontal layers of sampling ports having a vertical distance of $30 \mathrm{~cm}$. A porous medium having a grain size of $0.5-1.0$ $\mathrm{mm}$ free from organic content was packed homogeneously for conducting steady state experiments. To see the role of drainage flux, recharge flux and infiltration on (un)-saturated zone flow, the multiple sets of the simulation experiment were conducted considering- a) Applying drainage and recharge flux to study domains b) transient infiltration in a vertical soil column c) Subsequently, the role of transient water flow on nitrate transport was evaluated using sand tank practical and simulation experiments. The simulation overview is presented in figure 1 and evaluated in the HYDRUS software projects using the different initial and boundary condition.

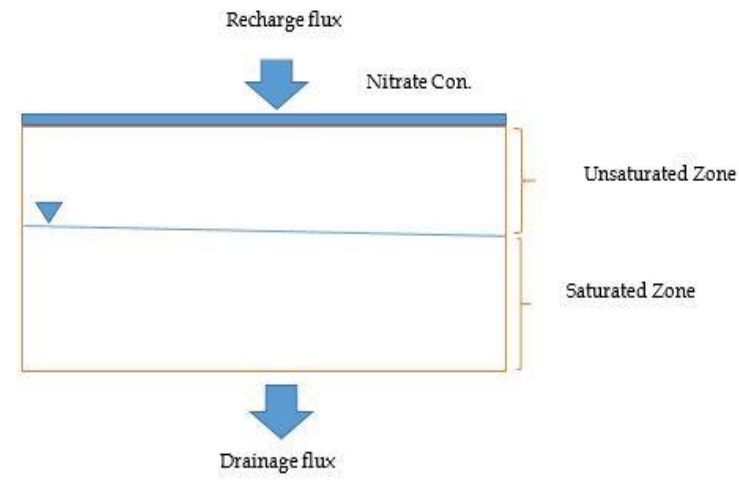

Figure 1: Overview of the methodology adopted to see the role of drainage, recharge flux on transient flow and nitrate transport.

In the case of a, firstly the drainage to two-dimensional domains under transient condition considered a $6.00 \mathrm{~m} \times 2.00 \mathrm{~m}$ saturated porous medium which allowed to drain after a sudden drop in the external water table. During the entire transient drainage phase, pressure heads and water contents were measured till the condition of steady-state was reached. No-flow boundaries are to be considered at the bottom, top and the left side (accounting for the symmetry) in the flow model. A height (h) of $1.45 \mathrm{~m}$ is to be maintained for the water table before drainage. The soil parameters are $\theta \mathrm{s}=0.3, \theta \mathrm{r}=0$, $\mathrm{K}$ 's $=9.6 \mathrm{~m} /$ day. The transient simulation is continued until steady state is approached. Secondly, water table recharge to two-dimensional domains considered $6.00 \mathrm{~m} \times 2.00 \mathrm{~m}$ rectangular soil domain with $h^{\prime}=0.65 \mathrm{~m}$. A constant flux of $\mathrm{q}=3.55 \mathrm{~m} /$ day was applied at the soil surface over a width of 0.5 $\mathrm{m}$ on the top of the flow domain, the remaining soil surface at the top is a no-flow boundary. The water table level on the right face of the slab is maintained at $0.65 \mathrm{~m}$, and a no-flow boundary is applied above the water table on the right side of the flow domain. The soil parameters are $\theta \mathrm{s}=0.30$, $\theta \mathrm{r}=0.01, \alpha \mathrm{v}=3.3 \mathrm{~m}-1, \mathrm{nv}=4.1$ and $\mathrm{K}$ 's $=8.40 \mathrm{~m} /$ day. Similarly, in the case of $\mathrm{b}$, transient infiltration in a vertical soil column the constant flux of $3.29 \mathrm{~m} /$ day is imposed at the soil surface and the lower end of the column has a constant pressure head of $\psi=-0.615 \mathrm{~m}$. The time of infiltration is 0.8 hours. The flow section is modeled as a rectangular column, $0.70 \mathrm{~m}$ tall and $0.05 \mathrm{~m}$ wide. The soil parameters are $\theta \mathrm{s}=0.287, \theta \mathrm{r}=0.075, \mathrm{~K}$ 's $=8.16 \mathrm{~m} /$ day. Both sides of the flow are analyzed with no flow boundary condition. In all simulation, the different hydraulic parameters were estimated and compared with the experimental values. For all the geometry domain in the HYDRUS, the Van Genuchten- Mualem model as a single porosity model was selected as the soil hydraulic model with no any hysteresis effects. The Finite Element Mesh Generator dialog window was used in earlier versions to select a structured finite element mesh for relatively simple rectangular or hexahedral domain, or a more general unstructured finite element mesh. 


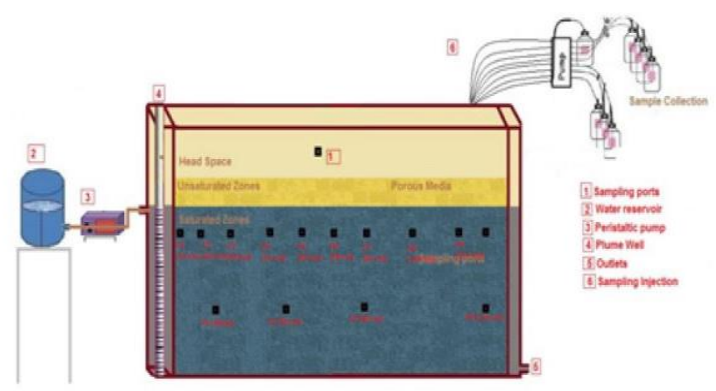

Figure 2: Schematic diagram of the two-dimensional sand tank setup indicating the (un)- saturated zone and sampling ports.

\subsection{Experimental media}

The medium sand having particle size $0.5-01 \mathrm{~mm}$ used as experimental media. The physiochemical properties of the experimental media described in table 1. The India standard (IS) porous media 650 grade-II having less than $1 \mathrm{~mm} \&$ greater than $0.5 \mathrm{~mm}$ particle distribution sizes were used. Before use in the tank, sand was washed and oven at $105^{\circ} \mathrm{C}$ for 24 hours. The oven dried sands were used in the final setup of the sand tank. The physical and chemical properties of used media are represented in table 1 .

Table 1: Physical and chemical properties of the experimental porous media.

\begin{tabular}{|c|c|c|c|c|c|c|c|}
\hline $\begin{array}{c}\text { Porous } \\
\text { media type }\end{array}$ & $\begin{array}{c}\text { Sand }(\mathrm{g} \\
\left.\mathrm{hg}^{-1}\right)\end{array}$ & Silt $\left(\mathrm{g} \mathrm{hg}^{-1}\right)$ & $\mathrm{pH}$ & $\mathrm{EC}$ & $\mathrm{OM}^{\mathrm{a}}$ & $\begin{array}{c}\text { Bulk Density } \\
\left(\mathrm{g} / \mathrm{cm}^{3}\right)\end{array}$ & $\begin{array}{c}\text { Dimension } \\
\left(\mathrm{l}^{*} \mathrm{~h}^{*} \mathrm{w}\right) \mathrm{cm}\end{array}$ \\
\hline Sandy soil & 92.8 & 4.2 & 5.5 & 4.9 & $0 \%$ & 1.65 & $300 \times 200 \times 10$ \\
\hline
\end{tabular}

\section{RESULTS AND DISCUSSIONS}

The focus of this study is to investigate the role of drainage, recharge flux and infiltration on the subsurface flow and subsequently, the nitrate dynamics in partially saturated zones. The different observed and simulated results are presented in different sub-section as below-

\subsection{Impact of drainage flux on water table:}

The drainage flux was applied at the bottom boundary of the 2D domain having the transient condition and the measured and simulated position of the water table at a different time were plotted in figure 3. The results show the lowering of water table occurs with the progression of time. This shows the increasing drainage flux causes the lowering of water table i.e. extension of unsaturated zones.

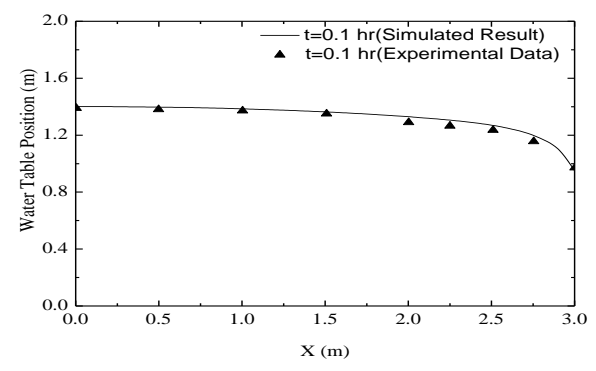

a) $0.1 \mathrm{hr}$. 


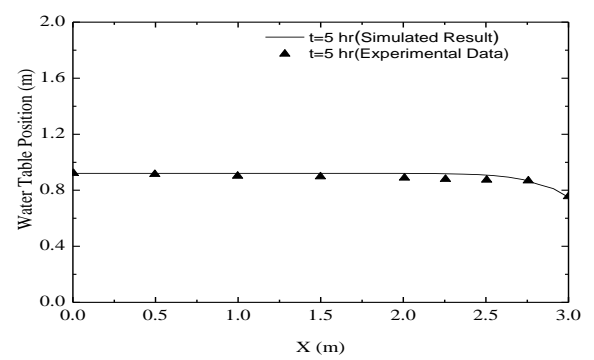

b) $5 \mathrm{hr}$.

Figure 3: The water flow profile in the case of the drainage to two-dimensional domains under transient condition a) $0.1 \mathrm{hr}$. and b) 5 hours.

\subsection{Impact of recharge flux on water table}

The recharge flux was applied at top boundary of the 2D domain under transient condition. The water table change in two-dimensional domains under transient condition showed the increasing trends for experimental as well as simulated condition. The results plotted in figure 4.

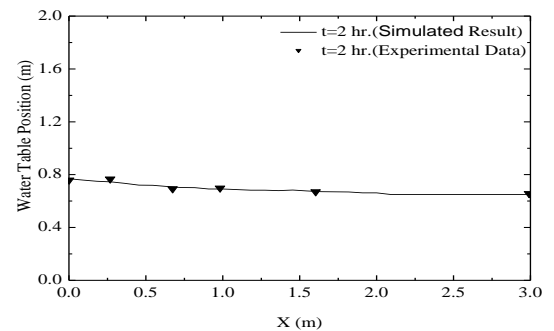

a) $2 \mathrm{hr}$.

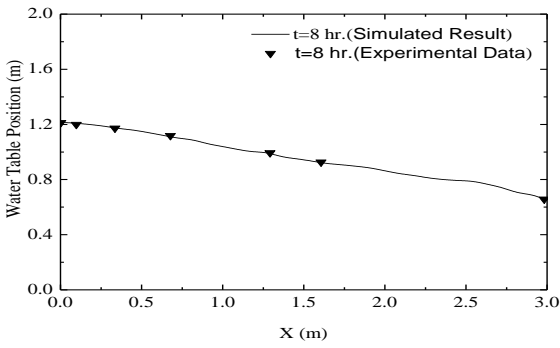

b) $8 \mathrm{hr}$.

Figure 4: The water table profile in the case of the recharge flux under the transient condition, a) $2 \mathrm{hr}$. and b) 8 hours

\subsection{Transient infiltration in column setup}

The water flux was allow to flow in the vertical direction and the measured and simulated results show the decreasing water table elevation with increasing water content (figure 5). The water movement shows faster for the domain and increases with depth as water flux applied on the top boundary. 


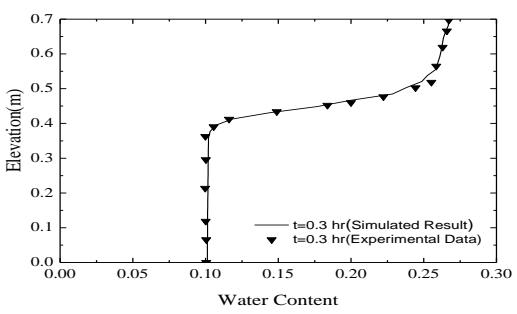

a) $0.3 \mathrm{hr}$

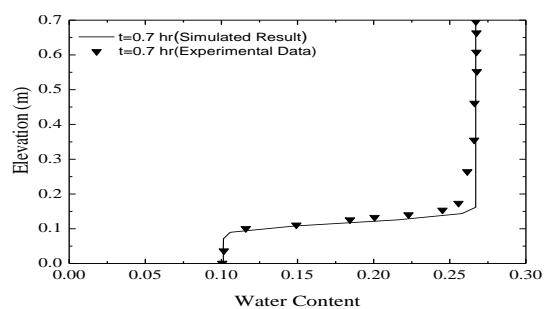

b) $0.7 \mathrm{hr}$.

Figure 5: The water flow in the case of the transient infiltration at, a) $0.3 \mathrm{hr}$ and b) 0.7 hours

\subsection{Role of transient water flow on nitrate Transport Dynamics: A case study}

A constant flux of nitrate a selected conservative solute allowed flowing in the horizontal direction in a two-dimensional domain. The BTCs shows the nitrate concentration increases with time and reached to the peak concentration, there after its decreases with the evolution of time in figure 6 . Initially, the top observation points (P1-P9) having high peak concentration, which decreases with increasing concentration of middle (P10-P14). This shows that nitrate transported horizontally due to advective flux and towards the downwards by dispersive flux. The advective flux dominated transport is highly affected by the recharge flux in the vertical direction. Therefore, the recharge flux in an area having nitrate pollution causes more nitrate load ta groundwater table as it is transported with the subsurface flow.

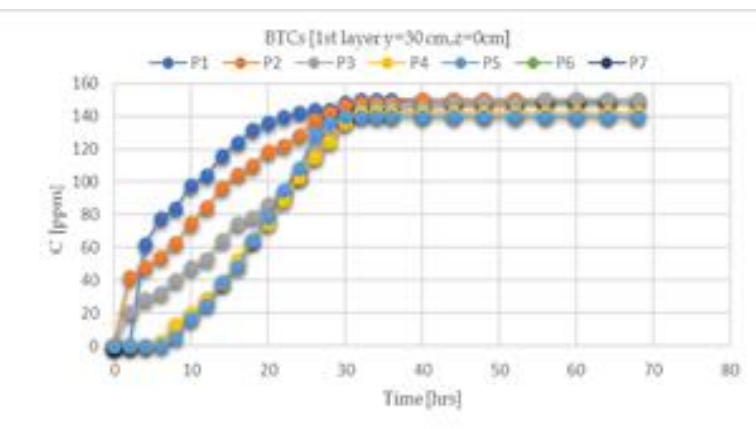

(a)

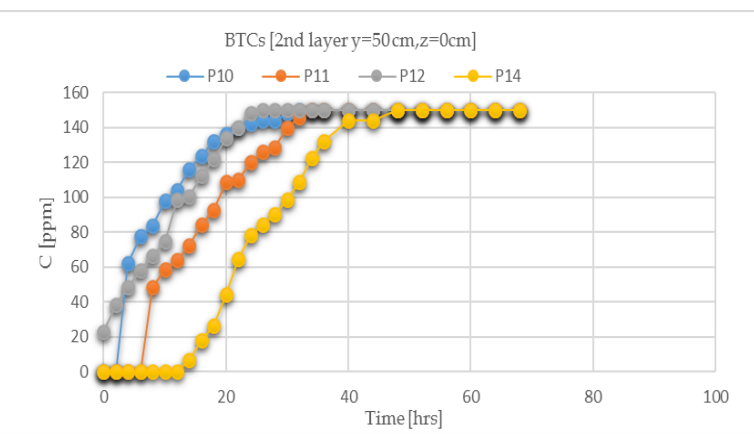

(b)

Figure 6: Experimental breakthrough curve of nitrate at different sampling ports installed in experimental setup (a) ports P1-P9 installed in 1st layer of porous media (b) port P10-P13 installed in 2nd layer of porous media (see figure 1 for location)

\section{CONCLUSION}

The focus of the study is to investigate the role of drainage, recharge flux, and infiltration on subsurface and subsequently, on nitrate movement dynamics in the subsurface. A series of laboratory 
and simulation experiments were conducted using 2-dimensional sand tank setup. A constant drainage flux was applied at bottom of the domain to see the impact on the water table and shows that water table position decreases as the time increase significantly. Similarly, a constant recharge flux was applied at the top boundary to see the impact on the water table and shows that water table position increases as the time increase significantly. In the last set, the constant water flux was applied on top to investigate the infiltration and the results show that the water flow profile shows the decreasing water table elevation with increasing water content in the vertical domain. Further, a constant flux of nitrate a selected conservative solute allowed flowing in the horizontal direction in a two-dimensional domain. The BTCs and concentration profile curves show that advective flux dominated transport is highly affected by the recharge flux in the vertical direction. Therefore, the recharge flux in an area having nitrate pollution causes more nitrate load ta groundwater table as it is transported with the subsurface flow. The results of this study may help in the protection of groundwater resources from vadose zone return flows and can be used directly in the planning of remediation strategies for the polluted sites.

\section{REFERENCES}

[1] Zhang, Zaiyong et al. 2015. "Finite Analytic Method for Solving the Unsaturated Flow Equation." Vadose Zone Journal 14(1): 1-10

[2] Van Genuchten, M. Th. 1980. "A Closed-Form Equation for Predicting the Hydraulic Conductivity of Unsaturated Soils1." Soil Science Society of America Journal 44(5): 892.

[3] Pruess, K., C. Oldenburg and G. Moridis. 1999. Lawrence Berkeley National Laboratory Report LBNL TOUGH2 User's Guide. Berkeley, CA.43134.

[4] Šimůnek, J, and M Šejna. 2008. "Modeling Subsurface Water Flow and Solute Transport with HYDRUS and Related Numerical Software Packages." Numerical Modelling of Hydrodynamics for Water Resources - Garcia-Navarro \& Playán (eds): 95-115.

[5] Yeh, T.-C. Jim, Rajesh Srivastava, Amado Guzman, and Thomas Harter. 1993. "A Numerical Model for Water Flow and Chemical Transport in Variably Saturated Porous Media." Ground Water 31(4): 634-44. doi:10.1111/j.1745-6584.1993.

[6] Srivastava, Rajesh, and T.-C. Jim Yeh. 1992. "A Three-Dimensional Numerical Model for Water Flow and Transport of Chemically Reactive Solute through Porous Media under Variably Saturated Conditions." Advances in Water Resources 15(August): 275-87.

[7] Šimůnek, J., D. Jacques, M. Th. van Genuchten, and D. Mallants. 2006. "Multicomponent Geochemical Transport Modeling Using the HYDRUS Computer Software Packages." J. Am. Water Resour. Assoc., 42(6): 1537-47.

[8] Therrien, R and Sudicky, E. 1996. "Three-Dimensional Analysis of Variably-Saturated Flow and Solute Transport in Discretely- Fractured Porous Media." Journal of Contaminant Hydrology 23(95): 1-44.

[9] Legout, C., J. Molenat, and Y. Hamon. 2009. "Experimental and Modeling Investigation of Unsaturated Solute Transport with Water-Table Fluctuation.” Vadose Zone Journal 8(1): 21.

[10] Celia, M. a., E. T. Bouloutas, and R. L. Zarba. 1990. "A General Mass-Conservative Numerical Solution for the Unsaturated Flow Equation." Water Resources Research 26(7): 1483-96.

[11] Mualem Yechezkel. 1976. "A New Model for Predicting the Hydraulic Conductivity of Unsaturated Porous Media." Water Resources Research 12(3): 513-22. 